\title{
RöKo für Studenten - kostenfreie Teilnahme und Sonderprogramm
}

Auch für Medizinstudenten ist der Kongress eine hervorragende Gelegenheit, mit der Vielfalt des Faches und seinen wissenschaftlichen Perspektiven in Kontakt zu treten. Wir laden Sie herzlich zum Kongressbesuch ein - die Teilnahme ist für Studenten kostenfrei! Registrieren Sie sich online auf www. roentgenkongress.de / Anmeldung wählen Sie hierfür die Option „Studenten" und schicken Sie Ihren Studentenausweis in Kopie an das Kongressbüro. Kurzentschlossene können sich auch vor Ort auf dem Kongressgelände noch registrieren - Studentenausweis zur Vorlagen nicht vergessen!

\section{Kongress-Sonderprogramm für Studenten}

Mit seinen hunderten von wissenschaftlichen Vorträgen, Refresher-Kursen und Workshops an vier Kongresstagen ist der RöKo der größte deutschsprachige Radiologiekongress. Daher bieten wir in diesem Jahr speziell für Studenten und Erstbesucher eine Einführungsveranstaltung rund um das Thema „Orientierung beim Kongress“ gleich am ersten Kongresstag an. Am Donnerstag gibt es dann in der Session "Alles im Blick in der Radiologie" die Gelegenheit in radiologische Themen einzutauchen.

Ein ganz besonderes Highlight werden erneut die „Sono4You“-Kurse sein: In diesen Hands-On-Kursen speziell für Studenten lernen Sie Ultraschall direkt am Gerät eben „Hands On“! Da die Teilnehmerzahl stark beschränkt ist, ist eine gesonderte Anmeldung und Buchung für diese Kurse

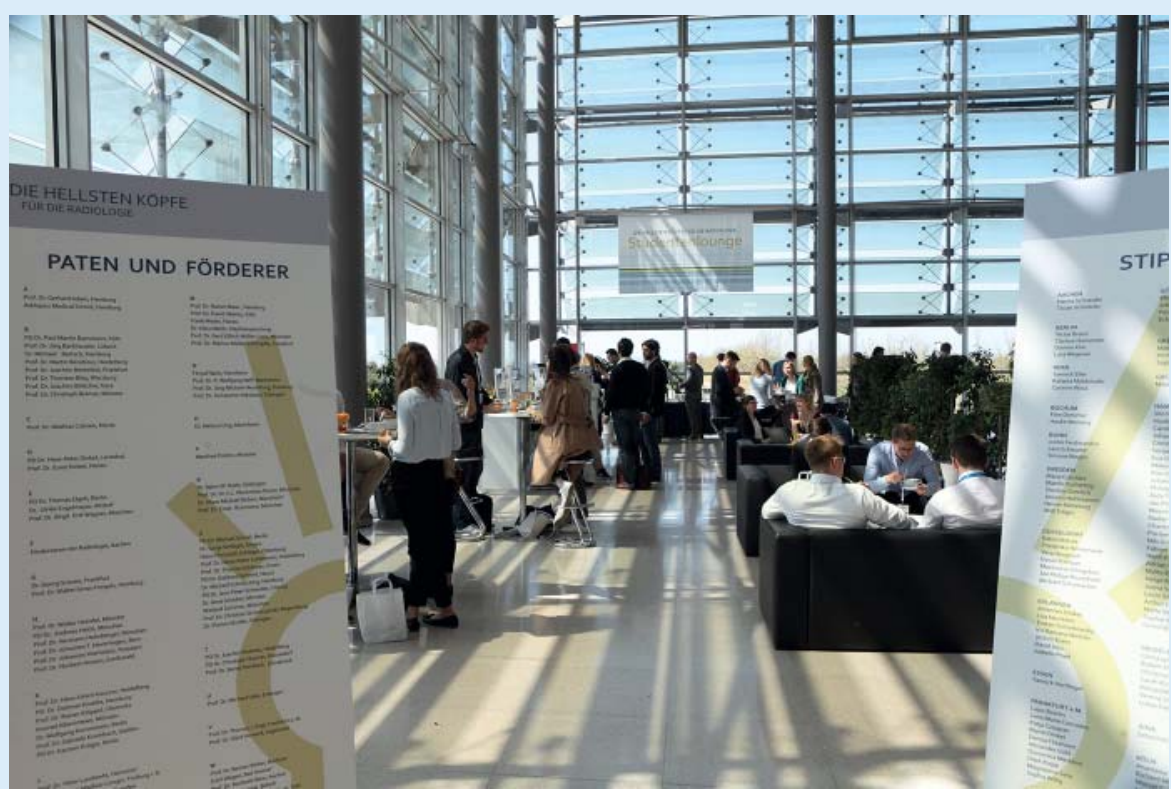

Die Studentenlounge finden Sie auf Ebene + 1 des Congress Center Leipzig (CCL) schräg gegenüber des Saales Röntgen. (copyright: DRG).

erforderlich. Alle Infos zum Studentenprogramm und den Sono4you-Kursen sowie zur Anmeldung finden Sie auf www.hellstekoepfe.de > Röntgenkongress 2017> Kongressprogramm für Studenten.

Erstmals wird es auf dem 98. RöKo einen Schnupperkurs für Interventionelle Neuro-/ Radiologie für Studenten geben. In Kleingruppen können die Studierenden die Eingriffe an Simulatoren selbst durchführen. Auch hier ist eine gesonderte Anmeldung erforderlich. Informationen finden Sie auf www.hellste-koepfe.de > Röntgenkongress 2017 > Schnupperkurs.

Ergänzend zum erfolgreichen Sono4youProgramm bieten wir Studierenden in $\mathrm{Zu}$ - sammenarbeit mit der Lernklinik Leipzig verschiedene Ultraschall-Workshops im Rahmen des 98. RöKo an. Die Workshops finden in Kleingruppen à 5 TN pro Gerät und Tutor statt. Eine gesonderte Anmeldung ist aufgrund der begrenzten Teilnehmerzahl erforderlich. Weitere Informationen finden Sie auf www.hellste.koepfe.de > Röntgenkongress 2017 > Lernklinik Leipzig.

\section{Die Studentenlounge als erste Anlaufstelle}

Auf der Ebene + 1 finden Sie die Studentenlounge - ein Fixpunkt gerade für Erstbesucher im "Dschungel" des umfangreichen Kongressangebots. Hier treffen Sie an allen 
Tagen einen Ansprechpartner, können sich mit anderen Studenten austauschen und an Internet-Terminals den weiteren Kongressbesuch planen.

\section{www.hellste-koepfe.de}

Viele Infos rund um Studenten beim Röntgenkongress finden Sie auch unter www. hellste-koepfe.de, dem Internetportal der DRG für junge Radiologen und Studenten, die im Laufe der kommenden Wochen noch erweitert werden - zum Beispiel um die Kongresstipps für Erstbesucher! 